\title{
SIMULATION APPROACH FOR ANALYSIS OF THE INVENTORY CAPACITY For Filling ANd PACKaging Plants
}

\author{
Ilya Kukushkin, Alina Zavrazhina, Johann Grabenweger, \\ Branko Katalinic \& Damir Haskovic
}
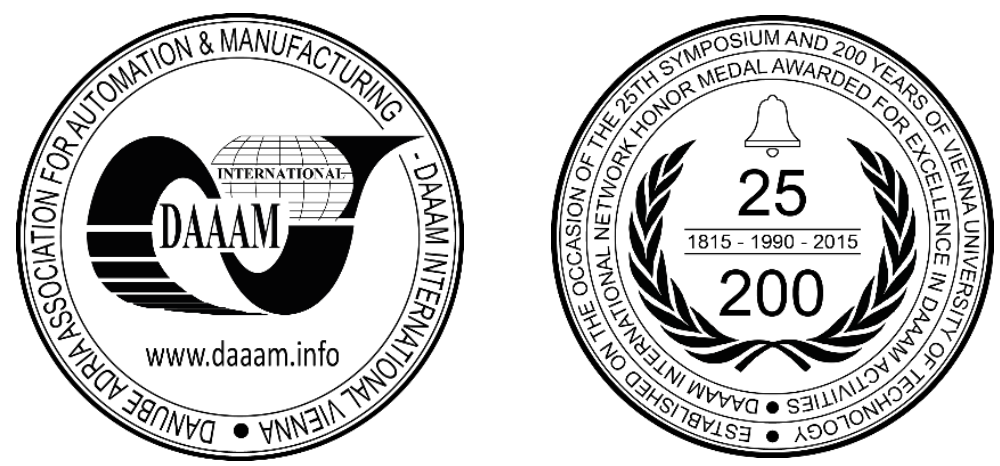

This Publication has to be referred as: Kukushkin, I[lya]; Zavrazhina, A[lina]; Grabenweger, J[ohann]; Katalinic, B[ranko] \& Haskovic, D[amir] (2016). Simulation Approach for Analysis of the Inventory Capacity for Filling and Packaging Plants, Proceedings of the 27th DAAAM International Symposium, pp.0876-0885, B. Katalinic (Ed.), Published by DAAAM International, ISBN 978-3-902734-08-2, ISSN 1726-9679, Vienna, Austria DOI: $10.2507 / 27$ th.daaam.proceedings.126

\begin{abstract}
This paper shows a new approach for the logistics analysis for modern filling and packaging plants. It compares different internal logistic strategies, considering the inventory sizes. The goal is to analyse the overall equipment effectiveness depending on each strategy using the simulation modeling.

The first experiment is to analyze the Just-in-time concept. Just-in time implies a lack of inventory. However, in real conditions the complete absence of inventory is impossible. Therefore, in the case of Just-in-time we creates the one storage rack that allows placing a small amount of pallets. In every new experiment the amount of storage racks will be increased by one. Running of the new experiments will cease when OEE value growth stops.
\end{abstract}

Keywords: Overall Equipment Effectiveness; Inventory; Warehouse space; Inventory Control Systems; Simulation.

\section{Introduction}

The main objective of any commercial organization is increasing of their own cash profit. The profit can be expressed by the following formula:

$$
\text { Profit }=(\text { Market Price }- \text { Production Costs }) \cdot \text { Output }
$$

Market Price is fixed for a manufacturer. However, the manufacturer can affect on the Production Costs and Output. The Formula 1 leads to the conclusion that the higher the Output value the higher the Profit. The Output depends on various factors. For instance, equipment breakdown, machines deterioration, production of defective products, etc. Analysis of all the factors influencing the Output is possible using the Overall Equipment Effectiveness (OEE). If OEE is $100 \%$ it means Output is maximum.

Any Production Costs result to a reduction in Profit. Production Costs consist of the Capital Expenditure (CAPEX) and Operative Expenditure (OPEX) [1].

OPEX includes day-to-day costs for the goods production. A list of these costs for filling and packaging plants are following: 
- Energy and electricity costs

- Packaging costs (preforms, labels, caps, foil, boxes, pallets)

- Labour costs

- Maintenance costs

CAPEX is an investment in equipment and buildings.

Therefore, three ways to increase Profit are:

1. To reduce CAPEX

2. To reduce OPEX

3. To increase output

To reduce the CAPEX costs is possible due to the reduction of the building and equipment costs. Savings on equipment may decrease the Output since production capacity reduces. The building costs can be decreased due to space reducing, for instance, warehouse space. Insufficient size of raw materials warehouse could cause a stoppage in production because of lack of raw materials. Lack of space at finished products warehouse could also cause the production stoppage since goods have to be stored under specific conditions. Both situations lead to the Output losses. Excessively large warehouses result to unnecessary costs for their construction (CAPEX) and their further maintenance (OPEX). The problem is to find the golden mean between the warehouses size and OEE.

In our previous paper we described a development of a simulation model of the filling and packaging line [2]. The model allows to carry out the overall equipment effectiveness analysis in case of different situations emerging on the filling and packaging lines. In the present paper we supplement the current model with elements of logistics and carry out experiments to search for optimal inventory size for the particular packaging plant.

\section{Inventory control system}

Companies should be flexible since customer's desires can be very diverse and changeable. The company satisfying the customer's needs before all competitors gets a project and all profit. Effective inventory control system allows to manage customer demand and to reduce inventory and storage costs [3]. There are two systems of inventory control: push and pull.

Push system means a production of enough amount of product to meet the consumer's demand. Producers are forced to predict how many products should be produced. Inaccuracies of demand forecast can be the cause of excess in the warehouse. It results in additional inventory and storage costs [4].

Examples of push systems are the MRP and MRP II strategies [5]. They are implemented as an application package. MRP provides coverage of the enterprise resources and enables the operational, manufacturing and financial planning.

Pull system are characterized by production of enough product to carry out customer's orders. The advantage of pull system over the push system is minimization of the inventory size and it leads to a decrease of storage costs [4].

The most widespread logistical concept in the literature is the Just-in-Time» (JIT). It implies that the components from the previous operation are delivered to next operation at the precise moment when they are needed, but not before. This approach reduces costs by eliminating the warehouse space [6]. In other words JIT is example of pull system. On the other hand if a supplier of raw materials can't deliver the raw material at exactly specified time, it could result in losses or even completely stop of the production process.

The available today theoretical methods and computer systems such as ERP and MPR give only approximate recommendations to minimize inventory in case of warehouse design development.

To see how effectively inventory management functions and what changes is reasonable to accept became possible with simulation modeling. The capacity of modern computer systems and the presence of professional software makes it possible the development of the factory simulation model and conducting experiments on a variety of processes taking place at the plant.

The simulation doesn't suppose a rejection of the technologies listed above. It offers their joint use because many of useful features already built into these systems.

\section{Description of the production line}

The initial model is developed for soft drinks filling and packaging line. The line can be configured to work with 1.5 and 0.5-liter PET bottles. In both cases the bottles are blown from preforms directly in the line. The production line represents a number of machines connected with each other through conveyors. List of machines and description of their functions are shown in Table 1. 


\begin{tabular}{|l|l|}
\hline Machine name & \multicolumn{1}{|c|}{ Function } \\
\hline Blower & $\begin{array}{l}\text { Intended for the production of plastic bottles by } \\
\text { blowing them out preforms. }\end{array}$ \\
\hline Mixer & Mixes the ingredients to get the finished beverage \\
\hline Filler & $\begin{array}{l}\text { Fills the beverage into the empty bottles and close } \\
\text { them with a cap. }\end{array}$ \\
\hline Labeling machine & $\begin{array}{l}\text { Pastes the label on the bottle filled with beverage. The } \\
\text { quality of gluing is checked. }\end{array}$ \\
\hline Packing machine & Packs bottles in six-pack or different packaging. \\
\hline Carry strip master & $\begin{array}{l}\text { Attaches the handle to the package for easy carrying } \\
\text { bottles. }\end{array}$ \\
\hline Palletizer & Lays out received boxes on pallets. \\
\hline Pallet wrapper & Tightens the pallet with a protective foil. \\
\hline
\end{tabular}

Table 1. Description of the machines functions

Line is formed in 2-block design, which means that the blowing and filling machines are interconnected in one block. The only accumulation table is located between filling and labeling machines, as shown in Fig.1. Other conveyors are not designed for additional accumulation.

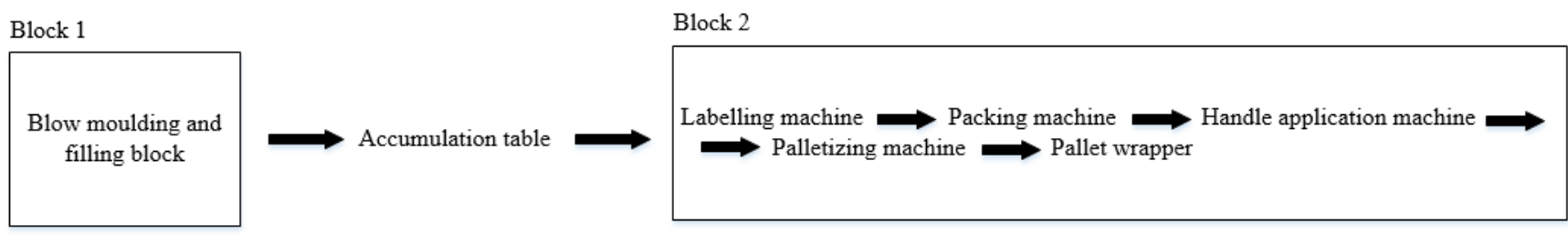

Fig. 1. 2-block design

The input information about orders contains following fields:

- Beverage Sort type (Cola, Cola light, carbonated water, etc.)

- Bottle volume, 1

- Lot size, bottle

- Type of label

- CIP matrix including cleaning time before the order and cleaning time after the order, sec

- Changeover matrix including changeover time before and after the order, sec

\section{The warehouse description}

The warehouse area is divided into two parts:

- Raw material warehouse

- Finished products warehouse

It is necessary to $\mathrm{pr}$

2 .

ovide the presence of loading zone and discharge zone for transport. The layout plan of warehouse is shown in Figure

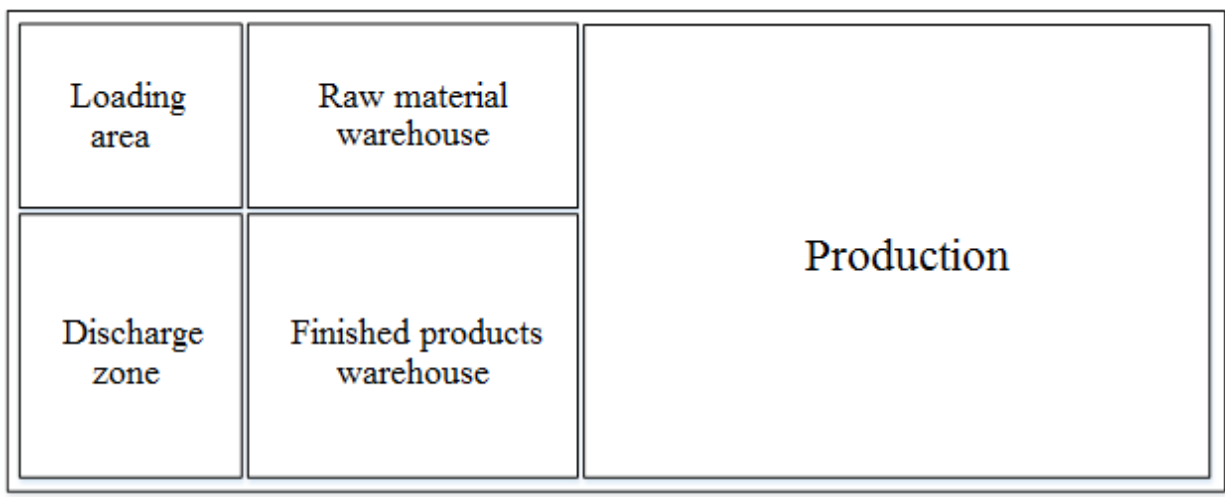

Fig.2. Layout plan of warehouse 
There are two groups of forklifts working in warehouse. The first group is engaged in loading and unloading of coming trucks and the second group delivers raw materials to machines, unused materials back to the raw material warehouse and finished goods to finished products warehouse. Passages for forklifts are provided between storage racks.

\section{Model development}

Simulation model is designed with the use of professional tools Anylogic. This program allows to solve problems in various fields of modeling: discrete event, system dynamics and agent based modeling. The main difference of AnyLogic from other existing solutions is the ability to combine and simultaneously use different modeling paradigms in the development of one model. It allows to create complex models, which are most compatible with the real production. Developed model consist of two simulation methods - agent-based and discrete-event modeling. Discrete-event simulation allows to observe the processes occurring at the production line and agent-based modeling allows to set up machine behavior logic. Integration of Java compiler in AnyLogic opens up almost unlimited possibilities for the model development.

\subsection{Warehouse development}

Discrete event simulation is most often used in the simulation of queuing systems, production processes and logistics [7]. Discrete Event modeling approach is implemented in AnyLogic using Enterprise Library. Enterprise Library is full of a variety of objects that allows to perform various operations. For example, the capture of the resource, the delay, the creation and destruction of the agents, etc.

Distributors trucks have an access to the discharge area and trucks from suppliers have an access to the loading area. Trucks have different capacity, customizable via such variables as ShippingTruckCapacity and TruckCapacity respectively. Also maximum movement speed for trucks on the territory was specified via variable TruckSpeed.

Warehouse can be represented by the following elements of Enterprise Library (Fig. 3).

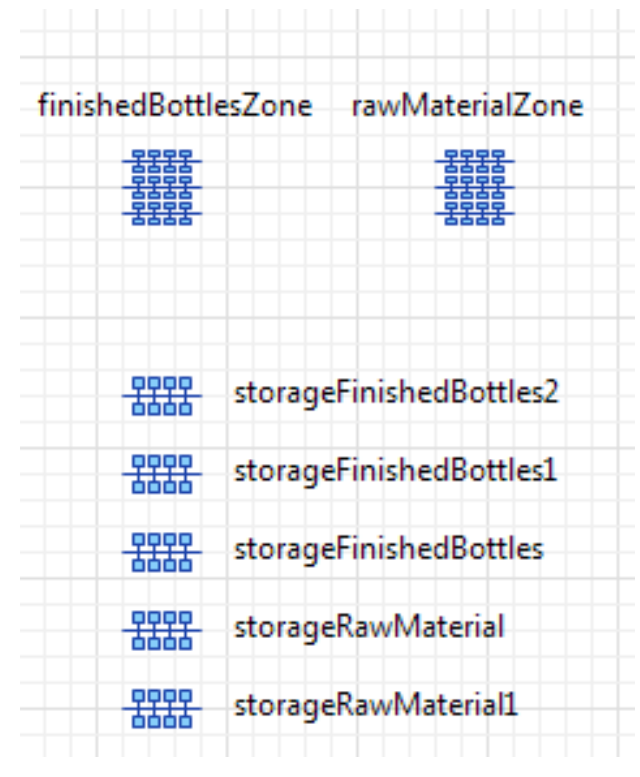

Fig. 3. Warehouse elements

Two groups of forklifts are connected with model (Fig. 5).

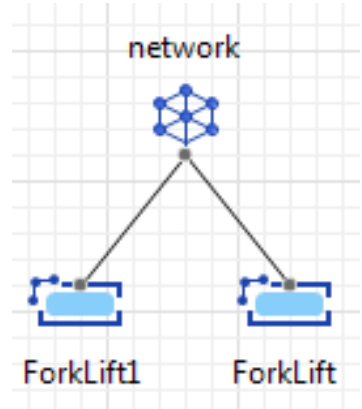

Fig. 4. Model network 
Each storage rack can be developed according to individual design (Fig. 5).

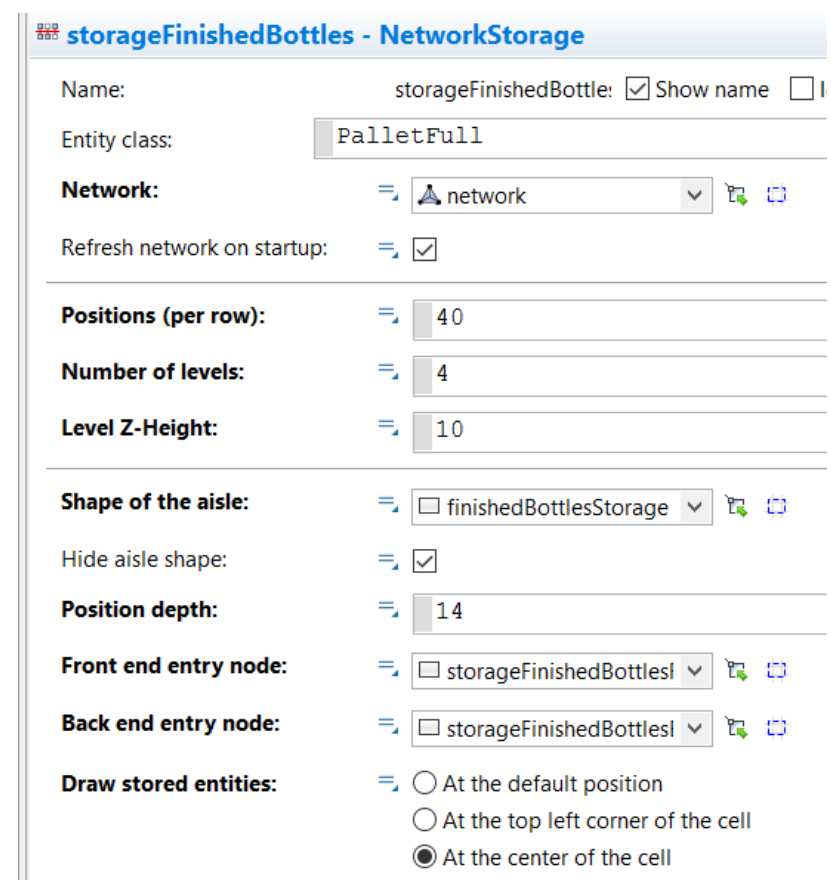

Fig. 5. Configuring of storage rack

The following processes were implemented by using the elements of standard library AnyLogic:

- Delivery of raw materials to the plant;

- Unloading of raw materials in the warehouse;

- Raw materials delivery from the warehouse to the machine;

- Transportation of the finished products to the warehouse;

- Shipment of finished products from the warehouse.

Figure 6 presents the process of delivery of raw materials to the plant, unloading of raw materials in the warehouse and delivery of raw materials from the warehouse to the machine. Truck advent causes the creation of preforms boxes and set a schedule for the delivery truck. Configuring the number of preforms into one box is easily adjusted by changing variable BoxsCapacity. Then the boxes with preforms are loaded into the truck and go to the loading area. After these operations there is branching: preforms are sent to the raw material warehouse and the truck is waiting in the loading until all boxes with preforms will be removed from it. RestrictedAreaStart RestrictedAreaStop elements set a limit on the number of preforms boxes that one forklift can carry. BoxAtMachine element lets forklift to know when it should stop the boxes delivery to machine. Then dropoffRawParts element opens the boxes and provides the preforms to Blower.

From time to time a Changeover happens on the line. In reference [8] the following changeover concept is gaven: changeover is the process of converting a line or machine from running one product to another. In this case we need to pick up the rest of PETs, labels and caps and bring them back to the raw material warehouse (Fig.7).

Almost every element requires a writing additional code. For example, Fig. 8 shows the code that calls a forklift with a box of caps for Filler.

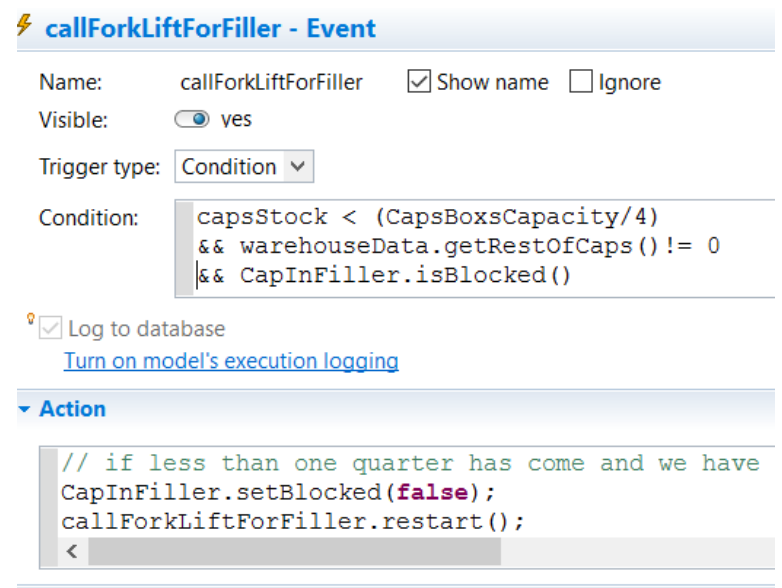

Fig. 8. Event of forklift call 
Figure 9 shows the processes of transporting finished products to the warehouse and the shipment of finished products from the warehouse.

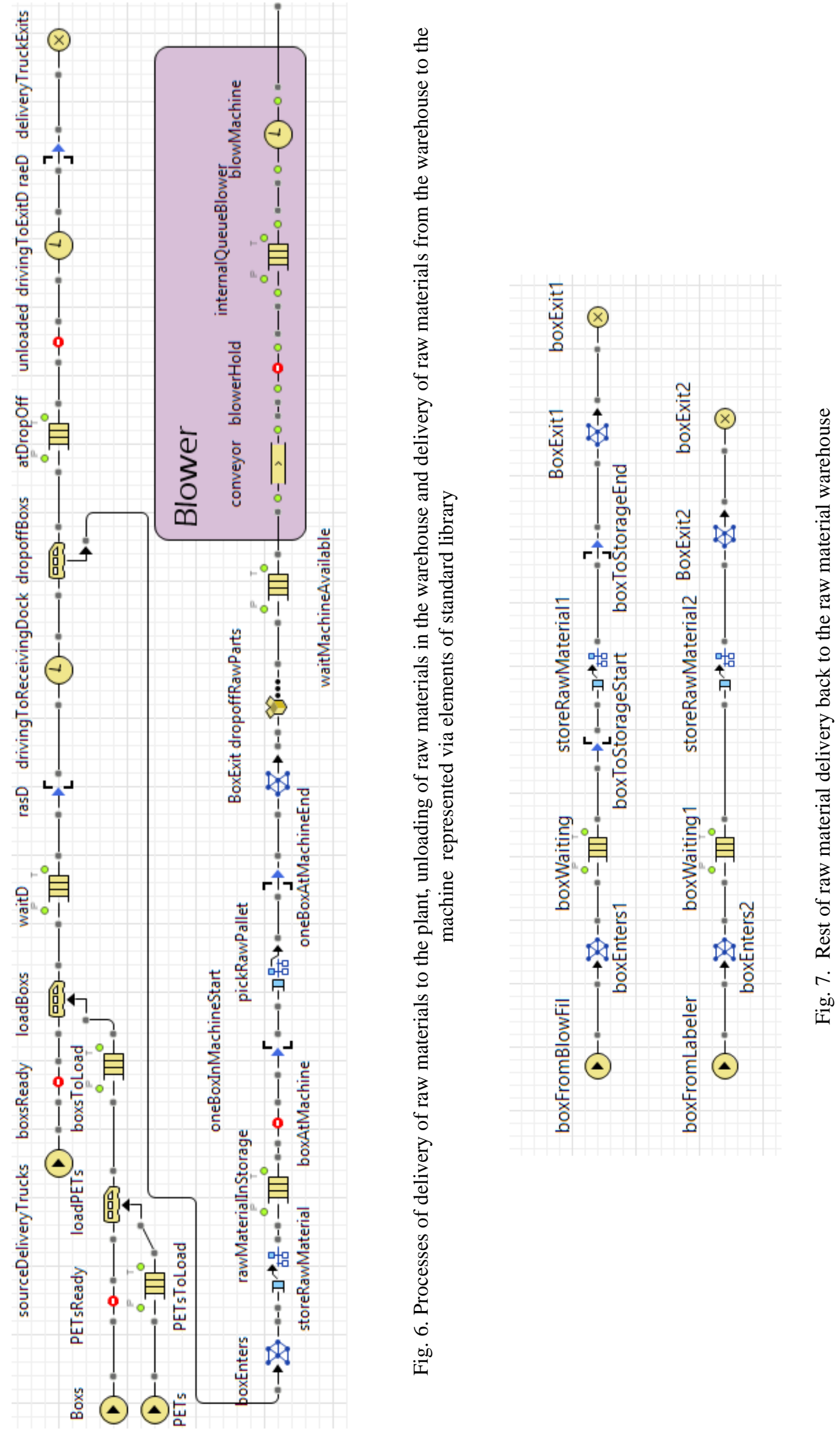




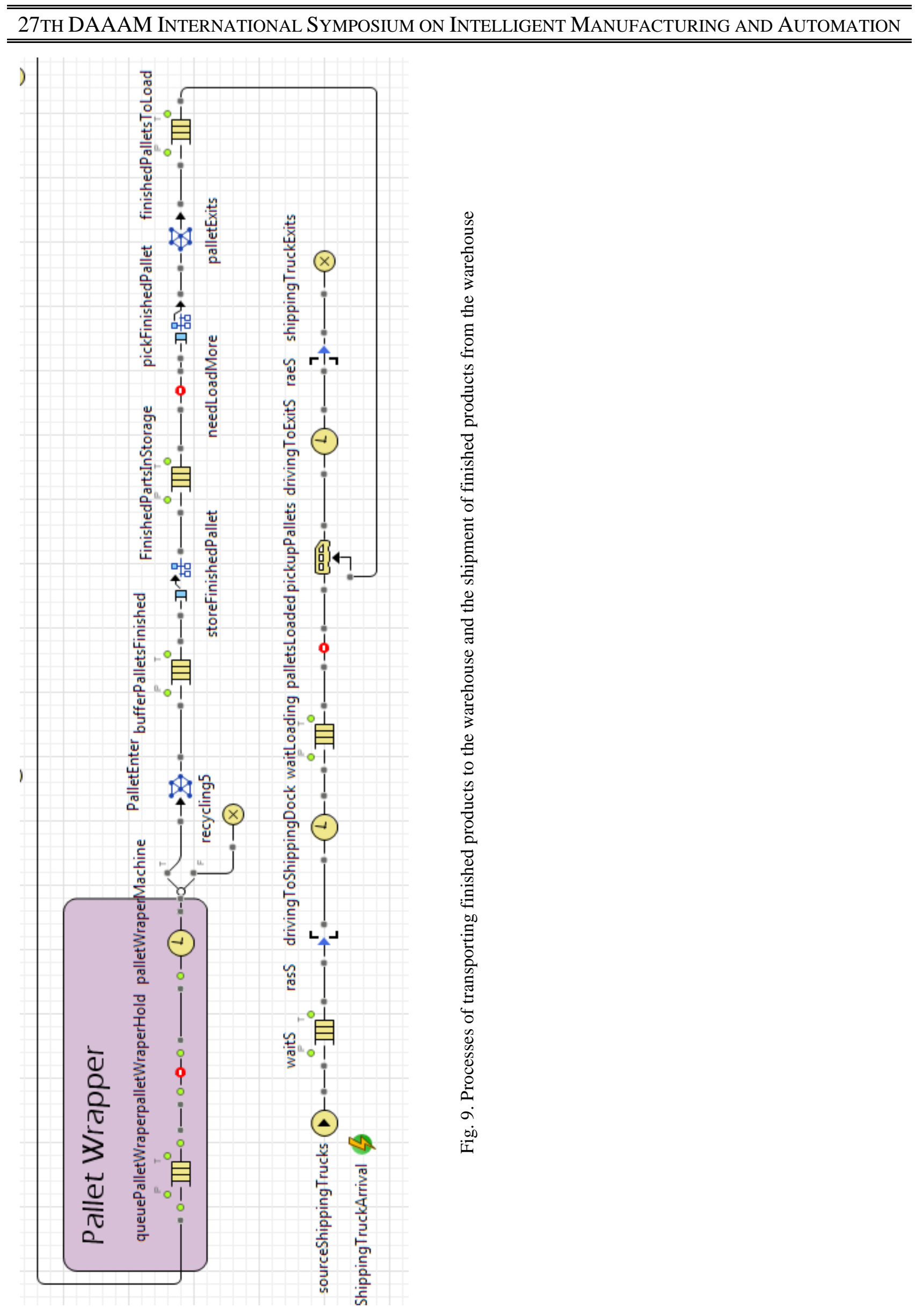


Pallet Wraper wraps pallets by protective film. Than they includes in the network, where they are picked up by trucks and unloaded at the warehouse for further storage. When Shipping Truck Arrival event is active the trucks come for shipment of the finished products. Also truck stop was provided in the discharge zone as long as the tuck will be fully loaded.

The 2D graphics (Fig. 10) and Gantt chart (Fig. 11) were developed to observe the functioning of the system.

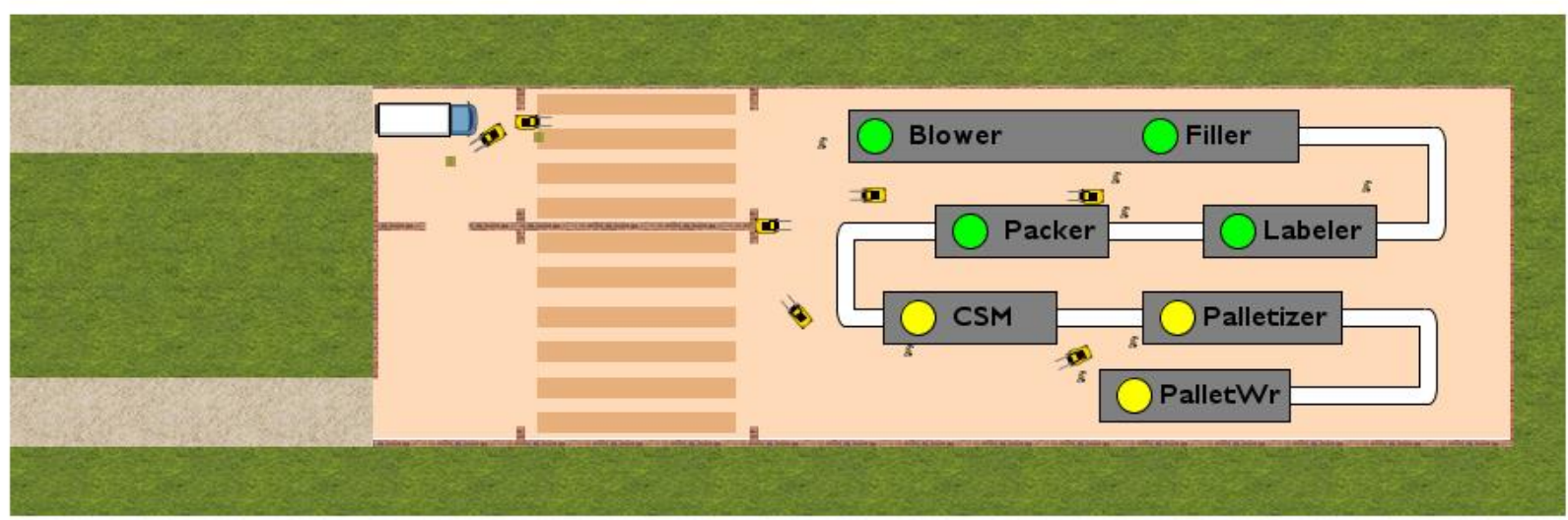

Fig. 10. 2D graphics of model

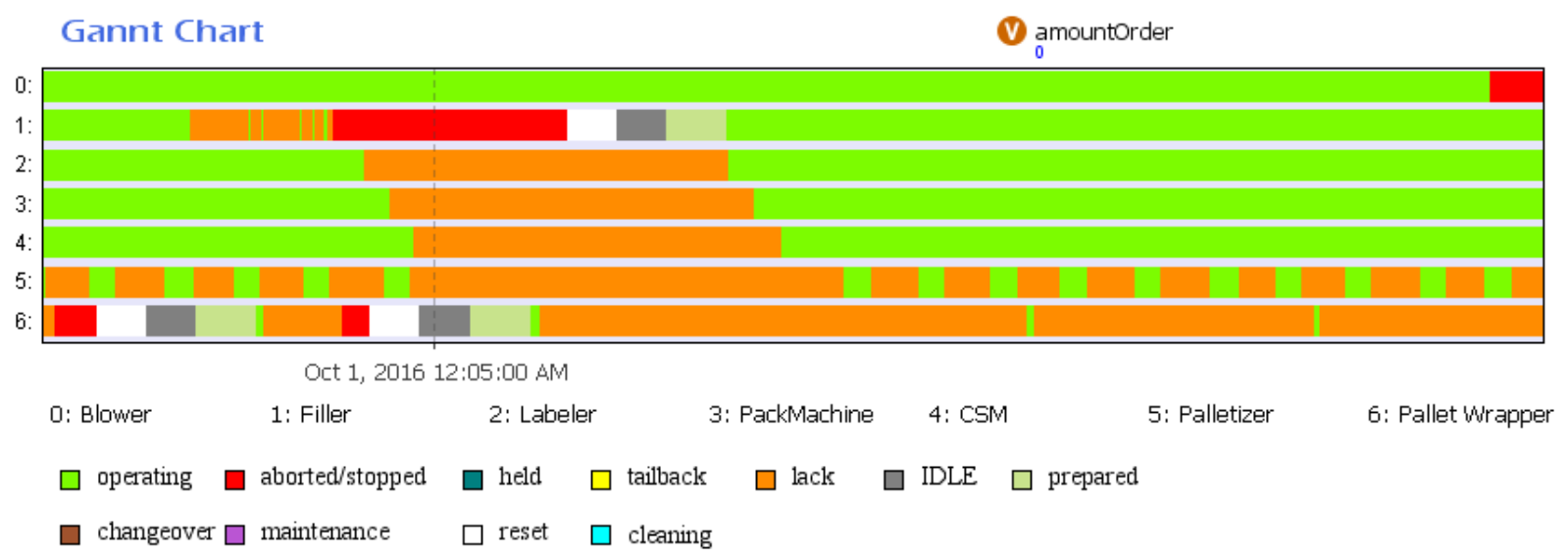

Fig. 11. Gantt chart

\section{Experiments}

The aim the experiment is to determine the optimal warehouse space for the particular plant. The first experiment is to analyze the Just-in-time concept. Just-in time implies a lack of inventory. However, in real conditions the complete absence of inventory is impossible. Therefore, in the case of Just-in-time we creates the one storage rack in raw material warehouse and one in finished products warehouse that allows placing a small amount of pallets. In every new experiment the amount of storage racks will be increased by one. Running of the new experiments will cease when OEE value growth stops.

The analysis is based on the value of overall equipment effectiveness. OEE is used for monitoring and improving production efficiency in the industry. The higher the OEE value the more effectively filler is used, accordingly the greater production output.

In case of raw materials warehouse workload, the call of truck will be canceled. Stop of production does not occur immediately because the other machines can continue working on conditions the free space in buffer. However, the lack of space in the finished products warehouse can lead to production stop. The resumption of production will begin after free up space at least for one pallet.

Table 2 gives the simulation results. The first experiment shows the Just-in-Time situation. In each subsequent experiment we add the extra storage racks.

In second and third experiments the drop sizes increase due to increasing of raw material warehouse space. Average utilization of raw material zone has the average performance because new supplies can come with a delay. Delays in the supply of raw materials are generated by asymmetric triangular distribution, where the minimum value is 0 hours, maximum value is 7 hours and most likely is 3 hours. 
Further increase of raw material warehouse does not lead to a significant performance improvement, therefore the third experiment is taken in the following experiments. In fourth and fifth experiments we add extra storage rack in finished products warehouse (Table 3 ).

\begin{tabular}{|l|l|l|l|}
\hline & \multicolumn{1}{|c|}{$\begin{array}{c}\text { Just-in-Time } \\
\left(\mathbf{1}^{\text {st }} \text { Experiment }\right)\end{array}$} & \multicolumn{1}{|c|}{$\begin{array}{c}\text { 1 extra storage rack } \\
\left(2^{\text {nd }} \text { Experiment }\right)\end{array}$} & $\begin{array}{c}\text { 2 extra storage rack } \\
\left(\mathbf{3}^{\text {rd }} \text { Experiment }\right)\end{array}$ \\
\hline & \multicolumn{2}{|c|}{ in raw material warehouse } \\
\hline OEE & 42.4 & 44.2 & 47.9 \\
\hline $\begin{array}{l}\text { Maximum Utilization of Raw } \\
\text { material zone, \% }\end{array}$ & 91.7 & 86.5 & 95.2 \\
\hline $\begin{array}{l}\text { Maximum Utilization of finished } \\
\text { bottles zone, \% }\end{array}$ & 97.8 & 97.8 & 97.8 \\
\hline $\begin{array}{l}\text { Average utilization of Raw material } \\
\text { zone, \% }\end{array}$ & 46.4 & 49.9 & 54.4 \\
\hline $\begin{array}{l}\text { Average Utilization of finished } \\
\text { bottles zone, \% }\end{array}$ & 81.8 & 82.9 & 84 \\
\hline Filler Utilization, \% & 43.7 & 43.9 & 45.6 \\
\hline Lead time, sec & 1039804 & 1038822 & 993967 \\
\hline
\end{tabular}

Table 2. The simulation results

\begin{tabular}{|l|l|l|}
\hline & $\begin{array}{l}\text { 1 extra storage rack } \\
\left(4^{\text {th }} \text { Experiment }\right)\end{array}$ & $\begin{array}{l}\text { 3 extra storage rack } \\
\left(5^{\text {th }} \text { Experiment }\right)\end{array}$ \\
\hline & \multicolumn{2}{|c|}{ in finished products warehouse } \\
\hline OEE & 49.3 & 50 \\
\hline $\begin{array}{l}\text { Maximum Utilization of Raw } \\
\text { material zone, \% }\end{array}$ & 85.7 & 85.1 \\
\hline $\begin{array}{l}\text { Maximum Utilization of finished } \\
\text { bottles zone, \% }\end{array}$ & 98.3 & 98.9 \\
\hline $\begin{array}{l}\text { Average utilization of Raw material } \\
\text { zone, \% }\end{array}$ & 52.8 & 52.3 \\
\hline $\begin{array}{l}\text { Average Utilization of finished } \\
\text { bottles zone, \% }\end{array}$ & 78.7 & 81.2 \\
\hline Filler Utilization, \% & 46.8 & 49 \\
\hline Lead time, sec & 977968 & 907101 \\
\hline
\end{tabular}

Table 3. The simulation results

Increasing of the finished products warehouse space has a strong impact on the lead time. The pallet wrapper will be stopped when there is no enough space in finished products warehouse. If the buffer placed in front of it is full, the palletizer will be also stopped and so on.

\section{Conclusion}

The simulation results show that the economy of warehouse space can lead to frequent production stops and bring the losses for manufacturer. Simulation have led to increasing of OEE from $42.4 \%$ to $50 \%$ and reduction of lead time by 132 703 seconds. We can take into account that one bottle makes a profit equals 1-euro cent, filler succeeds to fill from 8 to 10 bottles in one second depending on the volume of the bottle, the simulated scenario is performed for two weeks, and saved lead is 132703 seconds for two work weeks. By changing the warehouses sizes as it was shown in $5^{\text {th }}$ experiment the production output of 0.5-liter bottles will increase by 1327030 (filler capacity is 10 bottles/sec). The company's profits will be increased more than 10000 euros per every two work weeks or more than 25000 euros per year.

Simulation provides an opportunity to develop the warehouse design for a particular product line. The results demonstrate that the inventory capacity can significantly affect the downtime in production and consequently the final profit.

\section{References}

[1] Benaskar F. Cost analysis for a continuously operated fine chemicals production plant at $10 \mathrm{~kg} / \mathrm{day} \mathrm{using}$ a combination of microprocessing and microwave heating //Journal of Flow Chemistry. - 2011. - T. 1. - №. 2. - C. 74-89. 
[2] Kukushkin, I[lya]; Zavrazhina, A[lina]; Grabenweger, J[ohann]; Kildibekov, A[skar]; Katalinic, B[ranko] \& Haskovic, D[amir] (2016). Model-based concept for scheduling analysis of packaging lines, Proceedings of the 26th DAAAM International Symposium, pp.1149-1157, B. Katalinic (Ed.), Published by DAAAM International, ISBN 978-3-902734-07-5, ISSN 1726-9679, Vienna, Austria

[3] Axsater S. Inventory control. - Springer Science \& Business Media, 2007. - T. 90.

[4] Ghrayeb, Omar, Nipa Phojanamongkolkij, and Boon Aik Tan. "A hybrid push/pull system in assemble-to-order manufacturing environment." Journal of Intelligent Manufacturing 20.4 (2009): 379-387.

[5] Cochran, J. K., and H. A. Kaylani. "Optimal design of a hybrid push/pull serial manufacturing system with multiple part types." International Journal of Production Research 46.4 (2008): 949-965.

[6] Modak N. M., Panda S., Sana S. S. Optimal just-in-time buffer inventory for preventive maintenance with imperfect quality items //Tekhne. - 2015. - T. 13. - №. 2. - C. 135-144.

[7] Boev V.D. Computer simulation. Handbook for practical classes, course and diploma projects in AnyLogic 7/VAS, 2014. 432 p.

[8] Henry J.R. Achieving Lean Changeover: Putting SMED to Work/ Productivity Press, 2012. 205 p. 